\title{
Validation of Fat-Free Mass Estimation Using Prediction Equations in Male Patients with Chronic Obstructive Pulmonary Disease
}

\author{
Chandan Vinay Srigiripura, Asna Urooj, Chaya Sindaghatta Krishnarao ${ }^{1}$, Mahesh Padukudru Anand ${ }^{1}$ \\ Department of Studies in Food Science \& Nutrition, University of Mysore, 'Department of Pulmonology, JSS Medical College, JSS University, \\ Mysuru, Karnataka, India
}

\section{Abstract}

Context: The use of predictive equations in hospital settings lacking access to dual energy X-ray absorptiometry or bioelectrical impedance analysis (BIA) can be beneficial because cachexia, muscle wasting and related increase in morbidity and mortality are known occurrences in patients with chronic obstructive pulmonary disease (COPD). Aim: To analyse the predictive performance of reported equations for fat-free mass (FFM) prediction against BIA-derived FFM in patients with stable COPD. Design/Materials and Methods: Seventy-two male patients aged between 40 and 75 years with stable COPD were evaluated for FFM by BIA. FFM was also predicted for the same patients using equations reported by Kulkarni et al., Solomon Yu et al., Janmahasatian et al., as well as Deurenberg equation. Statistical Analysis Used: The predictive performance was assessed by Bland-Altman plots, with subsequent calculations of bias, precision and accuracy. The performance was also analysed across the age and body mass index sub-groups. Results: The mean differences (95\% confidence intervals) in the prediction of FFM using equations by Kulkarni et al. and Deurenberg equation were $-0.33 \mathrm{~kg}(-4.910,4.258)$ and $0.31 \mathrm{~kg}(-3.330,3.946)$, respectively. The equation by Solomon Yu et al. and Janmahasatian et al. overestimated FFM with a mean difference of 3.99 kg (-2.449, 10.428) and $3.76 \mathrm{~kg}(-0.443,7.956)$, respectively. Conclusion: The equation by Kulkarni et al. provides an acceptable prediction of FFM in patients who were underweight or had normal weight with COPD and were aged between 50 and 69 years. The Deurenberg equation was used to predict FFM in patients aged between 40-49 and 60-75 years. Further validation of the predictive performance in overweight and obese COPD patients is required.

Keywords: Anthropometry, bioelectrical impedance analysis, COPD, fat-free mass, prediction equation

\section{INTRODUCTION}

Chronic obstructive pulmonary disease (COPD) is a progressive respiratory disease characterised by persistent airway obstruction and inflammation. COPD is the fourth leading cause of death in the world with 3.2 million deaths globally in the year $2015{ }^{[1]}$ The systemic manifestations of COPD, important from a nutritional perspective, are weight loss, cachexia and muscle wasting or the loss of fat-free mass (FFM) ${ }^{[2]}$ FFM is a compartment of the body based on the two-compartment model and comprises of water, protein, minerals and glycogen, with the other compartment being fat mass. The techniques in body composition analysis allow for a non-invasive approach to assess and understand the body compartments and changes occurring in them because of normal life processes, disease conditions or an intervention. ${ }^{[3]}$ Recent research indicates fat-free mass index obtained from

\begin{tabular}{|l|l|}
\hline \multicolumn{2}{|c|}{ Access this article online } \\
\hline Quick Response Code: & Website: \\
& www.ijnpnd.com \\
\cline { 2 - 2 } & \\
& \\
\end{tabular}

the measurement of FFM as a better indicator of nutritional status in COPD patients. The major proportion of the weight lost in these patients is found to be FFM; thus, FFM measurement is a better indicator of nutritional depletion than body mass index (BMI) alone. Studies report patients having COPD with low FFM and normal BMI. ${ }^{[4,5]}$ FFM is also considered to be an independent predictor of mortality with negative consequences on the progression of the disease, exercise capacity and the quality of life of patients with COPD. ${ }^{[6,7]}$

\section{Address for correspondence: Dr. Asna Urooj, Department of Studies in Food Science \& Nutrition, University of Mysore, Manasagangotri, Mysuru - 570 006, Karnataka, India. E-mail: asnaurooj@foodsci.uni-mysore.ac.in}

This is an open access article distributed under the terms of the Creative Commons Attribution-NonCommercial-ShareAlike 3.0 License, which allows others to remix, tweak, and build upon the work noncommercially, as long as the author is credited and the new creations are licensed under the identical terms.

For reprints contact: reprints@medknow.com

How to cite this article: Srigiripura CV, Urooj A, Krishnarao CS, Anand MP. Validation of Fat-Free Mass Estimation Using Prediction Equations in Male Patients with Chronic Obstructive Pulmonary Disease. Int J Nutr Pharmacol Neurol Dis 2017;7:94-100. 
The measurement of FFM by the dual energy X-ray absorptiometry is accepted to be the gold standard for body composition analysis in these patients. ${ }^{[8]}$ The other commonly used methods for analysing body composition in research are computerised actual tomography, magnetic resonance imaging and bioelectrical impedance analysis (BIA). Majority of these methods are complex, require extensive labour, are costly and are not frequently available for use in clinical/nutritional practice. ${ }^{[9]} \mathrm{BIA}$ is relatively easy to practice and less expensive. In addition, the use of BIA for the determination of body composition has been validated. ${ }^{[4,10]}$ The evaluation of body composition based on anthropometric measures such as height, weight, skinfold thickness at various sites and/or the measurement of the arm, abdomen and calf circumference is a common practice in resource-limited settings. Such a practice involves the use of statistically validated prediction equations in comparison to standard assessment methods. ${ }^{[9]}$ Limited research is available on the validation of the use of predictive equations to estimate FFM in patients with COPD.

Considering the usefulness of the measurement of FFM in clinical settings lacking standardised equipment for FFM analysis, this study aims to assess the predictive performance of four FFM predicting equations using anthropometric variables against FFM derived by BIA using appropriate statistical methods.

\section{Materials and Methods}

\section{Subjects}

A total of 72 patients with stable COPD visiting the outpatient department of Pulmonology at JSS Multispeciality Hospital, Mysuru were selected consecutively for the study. Patients aged between 40 and 75 years without exacerbation of COPD, infection, evident oedema, heart disease, diabetes mellitus, renal failure and malignancy were included for the study after obtaining their informed consent. Ethical clearance was obtained from the Institutional Human Ethics Committee of University of Mysore (IHEC-UOM No. 100 Ph.D/2014-15 dated 07.08.2014) and JSS Hospital Mysore (JSS/MC/IEC/01/6903/2014-15 dated 03.03.2015). The pulmonary function was evaluated by spirometry (Easy one Pro LAB), and the staging of COPD was performed as per the global initiative for chronic obstructive lung disease classification. ${ }^{[1]}$ Height was measured using a stadiometer to the nearest $0.1 \mathrm{~cm}$, and weight was measured with the patients wearing light clothes. BMI was derived from the same.

\section{Estimation of fat-free mass of patients by bioelectrical impedance analysis}

The patients were analysed for FFM in a fasting state (or at least $4 \mathrm{~h}$ after a meal), with the patients lying in supine position for $10 \mathrm{~min}$ on a non-conducting surface with the legs slightly separated and the arms slightly away from the trunk. Surface electrodes were placed on the dorsal surfaces of the hand and foot proximal to the metacarpal phalangeal and metatarsal phalangeal joints, respectively. In addition, surface electrodes were also placed at the pisiform prominence of the wrist and between the medial and lateral malleoli of the ankle. ${ }^{[12]}$ The analyses were performed using a 'Bioscan 916' analyser $(50 \mathrm{kHz}$ single frequency, Maltron International Ltd, UK).

\section{Estimation of fat-free mass by prediction equations}

The age of the patients in the study group ranged between 40 and 75 years. Because there are no reported predictive equations for predicting FFM specifically for this age group (with COPD), four predictive equations were selected for validation keeping in mind the age range of the study group (40-75 years). The selected equations were developed in patients from both gender aged between 18 and 82 years. Among the four equations, three equations predicted FFM while the Deurenberg equation estimated fat mass (in \%). This was further converted to kilograms of fat mass and subtracted from the total body weight to obtain FFM values.

The four prediction equations chosen for analysis are as follows:

(1) Kulkarni et al. ${ }^{[13]}$

$$
\text { Lean mass } \begin{aligned}
(\mathrm{kg})= & -15.605-(0.032 \times \text { age in years }) \\
& +(0.192 \times \text { height in } \mathrm{cm}) \\
& +(0.502 \times \text { weight in } \mathrm{kg})
\end{aligned}
$$

(2) Solomon Yu et al. ${ }^{[14]}$

$$
\begin{aligned}
\text { Lean body mass }(\mathrm{kg}) & =22.93+0.68(\text { weight in } \mathrm{kg}) \\
& -1.14(\mathrm{BMI})-0.01(\text { age in years }) \\
& +9.94(\text { if male })
\end{aligned}
$$

(3) Janmahasatian equation ${ }^{[15]}$

$$
\begin{aligned}
& \text { Fat }- \text { free mass }(\mathrm{kg})_{\text {male }}=(9270 \times \text { weight }) / \\
& \left\{6680+\left(216 \times \text { BMI in } \mathrm{kg} / \mathrm{m}^{2}\right)\right\}
\end{aligned}
$$

(4) Deurenberg equation ${ }^{[16]}$

$$
\begin{aligned}
\text { Body fat }(\%) & =\left(1.2 \times \mathrm{BMI} \text { in } \mathrm{kg} / \mathrm{m}^{2}\right) \\
& +(0.23 \times \text { age in years }) \\
& -(10.8 \times \text { gender })-5.4 \\
& \text { Male }=1, \text { Female }=0
\end{aligned}
$$

\section{Statistical analyses}

The demographic data of the study population were expressed as mean and standard deviation (SD) or number and percentage, as appropriate. The Bland and Altman plot analysis was performed for the evaluation of the agreement 
between the predicted FFM and FFM by BIA, which involves the study of mean differences and establishes a limit of agreement into which $95 \%$ of the differences fall. The limits of agreement were defined as the difference between FFM values from each one of the selected predictive equations and FFM by $\mathrm{BIA} \pm 1.96 \mathrm{~s}$. The normality of distribution was assessed by Shapiro-Wilk test. ${ }^{[17]}$ The bias, precision and accuracy of the predictive equations were calculated for assessing the performance of the equations considering FFM values from BIA as standard with $95 \%$ confidence intervals. The bias was measured in terms of mean error, which is also known as 'mean difference', meaning the average of all the differences between FFM values by predictive equations and FFM by BIA. The 95\% confidence interval (CI) of the mean difference was calculated to analyse the precision of the systematic difference. The bias was considered to be insignificant when the line of equality was within this interval. The line of equality being outside these limits indicate constant over/underestimation compared to the standard measurement. ${ }^{[17,18]}$ The accuracy was defined in terms of the root mean square error (RMSE), which is the square root of the mean squared differences. ${ }^{[19]}$ The performance of the predictive equations was analysed on all the samples as a whole and after categorising them into sub-groups on the basis of BMI and age. The patients were categorised based on the BMI classification recommended for use among the South Asian population. ${ }^{[20]}$ All the statistical tests were performed using the Statistical Package for the Social Sciences version 19.0 software for Windows (SPSS Inc., Chicago, IL, United States).

\begin{tabular}{lc}
\hline \multicolumn{2}{l}{ Table 1: Demographic characteristics of the participants } \\
\hline Parameter & Mean \pm SD or $\boldsymbol{n}(\%)$ as appropriate \\
\hline Age (years) & $61 \pm 9.1$ \\
Gender - Male & $72(100 \%)$ \\
Height $(\mathrm{cm})$ & $166.47 \pm 5.78$ \\
Weight $(\mathrm{kg})$ & $58.38 \pm 12.56$ \\
BMI $\left(\mathrm{kg} / \mathrm{m}^{2}\right)$ & $20.99 \pm 4.13$ \\
Percentage of predicted $\mathrm{FEV}_{1}$ & $48.36 \pm 16.06$ \\
Percentage of predicted $\mathrm{FVC}$ & $70.22 \pm 16.78$ \\
FEV $_{1} / \mathrm{FVC}$ ratio & $0.55 \pm 0.09$ \\
\hline
\end{tabular}

$\mathrm{BMI}=$ body mass index, $\mathrm{FEV}_{1}=$ forced expiratory volume in $1 \mathrm{~s}$, $\mathrm{FVC}=$ forced vital capacity.

\section{Results \\ Characteristics of the subjects}

The age, anthropometric measures and pulmonary function of the patients involved in the study are presented in Table 1. The age of the patients ranged from 40 to 74 years. An age-wise distribution of the patients revealed 10 (13.9\%) patients in the age group of 40-49 years, 15 (20.8\%) aged 50-59 years, $32(44.4 \%)$ aged $60-69$ years and 15 $(20.8 \%)$ aged $70-75$ years. On evaluation of pulmonary function, $35(48.6 \%)$ patients were diagnosed with moderate COPD, 26 (36.1\%) patients with severe COPD, $8(11.1 \%)$ patients with mild COPD and $3(4.1 \%)$ patients with very severe COPD. The BMI of the patients ranged between 13.67 and $33.12 \mathrm{~kg} / \mathrm{m}^{2}$. Among the patients, based on their BMI, 22 (30.6\%) were underweight, 32 (44.4\%) were normally nourished, 5 (6.9\%) were overweight and 13 (18.1\%) were obese.

\section{Predictive performance of the equations}

The Bland-Altman plots comparing the FFM estimated by BIA and by the predictive equations are presented in Figure 1. The study sample follows normal distribution after the assessment of test of normality by Shapiro-Wilk test. The plots indicated best agreement between FFM by BIA and FFM predicted by the equations of Kulkarni et al. and the Deurenberg equation as evident by the proximity of the mean error near zero (a mean error of ' 0 ' indicates the absence of error in the predicted value). Statistically significant differences were absent between the BIA-derived FFM and FFM derived by the above mentioned equations on analysis by paired samples $t$-test. The mean error observed in the prediction of FFM by the equation of Kulkarni et al. and the Deurenberg equation was not significant because they included the line of equality in the $95 \%$ CI value for the mean error. The equation by $\mathrm{Yu}$ et al. and Janmahasatian equation overestimated the FFM values and had a significant mean error. The performance of predictive equations in terms of bias (mean error) and accuracy (RMSE) is presented in Table 2. Prediction equation by Kulkarni et al. and Deurenberg equation had the least bias, RMSE and SD compared to the equation by $\mathrm{Yu}$ et al. and Janmahastian equation, which overestimated the FFM values as measured by BIA. The CI values of the equation by Kulkarni et al. and Deurenberg equation indicate a near equal distribution of the

Table 2: Predictive performance of equations compared to FFM by BIA

\begin{tabular}{|c|c|c|c|c|c|}
\hline $\begin{array}{l}\text { FFM estimation methods } \\
(n=72)\end{array}$ & FFM (kg) Mean (SD) & Mean error $(95 \% \mathrm{Cl})(\mathrm{kg})$ & RMSE (95\% Cl) (kg) & Paired $t$-test, $P$ value & SEE \\
\hline FFM by BIA & $44.03(6.79)$ & - & - & - & - \\
\hline Kulkarni et al. equation & $43.71(6.86)$ & $-0.33(-4.910,4.258)$ & $2.35(-1.889,2.559)$ & $t(71)=1.182, P=0.241$ & 2.354 \\
\hline Solomon Yu et al. equation & $48.02(4.35)$ & $3.99(-2.449,10.428)$ & $5.11(1.761,6.219)$ & $t(71)=-10.518, P=0.000$ & 2.063 \\
\hline Janmahasatian equation & $47.79(6.82)$ & $3.76(-0.443,7.956)$ & $4.32(1.531,5.989)$ & $t(71)=14.881, P=0.000$ & 2.157 \\
\hline Deurenberg equation & $44.34(6.95)$ & $0.31(-3.330,3.946)$ & $1.83(-1.919,2.539)$ & $t(71)=-1.439, P=0.154$ & 1.824 \\
\hline
\end{tabular}

$\mathrm{FFM}=$ fat-free mass in $\mathrm{kg}, \mathrm{RMSE}=$ root mean square error, $\mathrm{BIA}=$ bioelectrical impedance analysis, $\mathrm{CI}=$ confidence intervals, $\mathrm{SEE}=$ standard error of estimate. 
Srigiripura, et al.: Bland-Altman plots of fat-free mass prediction equations
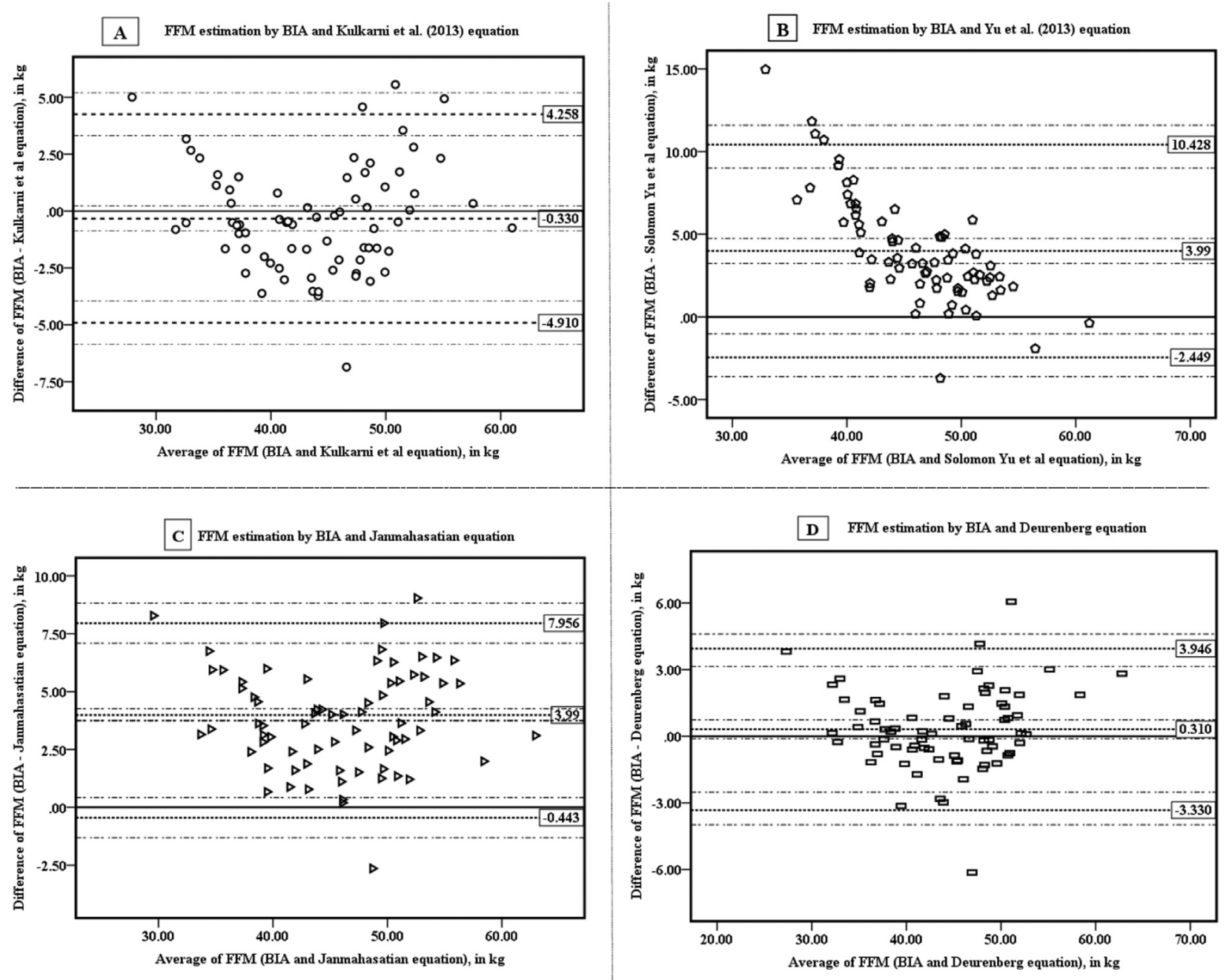

Figure 1: Bland-Altman plots comparing the FFM estimated by BIA and by the predictive equations $(n=72)$. Straight line $(-)$ indicates zero difference; (- - -) is the mean difference and upper and lower limits of 95\% confidence intervals; (- - -) indicates the limits of agreement for the mean difference and confidence intervals

upper and lower limits, that is an underestimation and overestimation to a similar extent. The other two equations indicate a higher proportion of overestimation of FFM values as evident by a higher upper limit value of CI than the lower limit values for both mean error and RMSE. Overall, the equations by Kulkarni et al. and Deurenberg equation appear to have the least bias and better accuracy than the other two predictive equations.

\section{Performance across body mass index sub-groups}

The performance of the equations across different BMI sub-groups is presented in Table 3. The Deurenberg equation exhibited lower bias and RMSE across all BMI sub-groups indicating better accuracy, precision and prediction followed by the Kulkarni et al. equation across underweight and normal BMI sub-groups. The other two equations constantly overestimated FFM values as evident by a higher mean error, as well as lower precision and RMSE values. The Deurenberg equation performed better than the other equations in the normal BMI group. In the overweight group, FFM by Deurenberg equation had the least mean error but similar RMSE as other equations. The prediction by Kulkarni et al. underestimated the FFM, whereas the prediction equation by Solomon $\mathrm{Yu}$ et al. and Janmahasatian equation overestimated FFM. The mean error in the prediction of FFM by the selected equations ranged from $0.75 \%$ in the equation by Kulkarni et al. to $9 \%$ in the equation by $\mathrm{Yu}$ et al. Overall, the Deurenberg equation had lower bias, as well as better precision and accuracy across underweight and normal BMI sub-groups. The equation by Kulkarni et al. displayed better prediction in the underweight group only. All the equations constantly overestimated FFM in the overweight and obese sub-groups as evident by lower precision and similar RMSE values.

\section{Performance across sub-groups classified according to the age}

The performance of the equations across different age groups is presented in Table 4. The Deurenberg equation had the best performance in the age group of 40-49 years as 
Srigiripura, et al.: Bland-Altman plots of fat-free mass prediction equations

\begin{tabular}{|c|c|c|c|c|}
\hline BMI groups & FFM estimation methods & Mean (SD) (kg) & Mean error $(95 \% \mathrm{CI})(\mathrm{kg})$ & RMSE (95\% CI) (kg) \\
\hline \multirow[t]{5}{*}{ Underweight $(n=22)$} & FFM by BIA & $36.18 \pm 4.33$ & - & - \\
\hline & Equation by Kulkarni et al. & $36.30 \pm 2.92$ & $0.12(-3.744,4.014)$ & $1.94(-2.109,2.349)$ \\
\hline & Equation by Solomon Yu et al. & $43.75 \pm 2.18$ & $7.57(1.962,13.179)$ & $8.05(5.341,9.799)$ \\
\hline & Janmahasatian equation & $40.19 \pm 3.16$ & $4.01(0.370,7.651)$ & $4.4(1.781,6.239)$ \\
\hline & Deurenberg equation & $36.59 \pm 3.22$ & $0.41(-2.505,3.317)$ & $1.48(-1.819,2.639)$ \\
\hline \multirow[t]{5}{*}{ Normal $(n=32)$} & FFM by BIA & $46 \pm 3.55$ & - & - \\
\hline & Equation by Kulkarni et al. & $44.48 \pm 3.44$ & $-1.52(-4.367,1.336)$ & $2.08(-3.749,0.709)$ \\
\hline & Equation by Solomon Yu et al. & $48.61 \pm 3.06$ & $2.61(-0.278,5.496)$ & $2.97(0.381,4.839)$ \\
\hline & Janmahasatian equation & $48.96 \pm 4.0$ & $2.96(1.960,6.269)$ & $3.39(0.731,5.189)$ \\
\hline & Deurenberg equation & $45.67 \pm 4.01$ & $-0.32(-2.835,2.186)$ & $1.28(-2.549,1.909)$ \\
\hline \multirow[t]{5}{*}{ Overweight $(n=5)$} & FFM by BIA & $46.72 \pm 2.73$ & - & - \\
\hline & Equation by Kulkarni et al. & $45.26 \pm 2.18$ & $-1.46(-8.349,5.43)$ & $3.47(-3.689,0.769)$ \\
\hline & Equation by Solomon Yu et al. & $48.15 \pm 2.05$ & $1.43(-5.252,8.108)$ & $3.31(-0.799,3.659)$ \\
\hline & Janmahasatian equation & $49.51 \pm 2.38$ & $2.79(-4.158,9.744)$ & $4.23(0.561,5.019)$ \\
\hline & Deurenberg equation & $46.23 \pm 2.01$ & $-0.48(-7.600,6.632)$ & $3.22(-2.709,1.749)$ \\
\hline \multirow[t]{5}{*}{ Obese $(n=13)$} & FFM by BIA & $51.46 \pm 4.3$ & - & - \\
\hline & Equation by Kulkarni et al. & $53.74 \pm 3.42$ & $2.28(-1.550,6.117)$ & $2.96(0.051,4.509)$ \\
\hline & Equation by Solomon Yu et al. & $53.77 \pm 2.79$ & $2.31(-1.734,6.358)$ & $3.02(0.081,4.539)$ \\
\hline & Janmahasatian equation & $57.11 \pm 3.04$ & $5.66(2.004,9.307)$ & $5.93(3.431,7.889)$ \\
\hline & Deurenberg equation & $53.46 \pm 4.27$ & $2.01(-1.520,5.533)$ & $2.63(-0.219,4.239)$ \\
\hline
\end{tabular}

$\mathrm{BMI}=$ body mass index, $\mathrm{FFM}=$ fat-free mass in $\mathrm{kg}, \mathrm{RMSE}=$ root mean square error, $\mathrm{BIA}=$ bioelectrical impedance analysis, $\mathrm{CI}=$ confidence intervals.

\begin{tabular}{|c|c|c|c|c|}
\hline Age group & FFM estimation methods & Mean (SD) (kg) & Mean error $(95 \% \mathrm{Cl})(\mathrm{kg})$ & RMSE $(95 \% \mathrm{CI})(\mathrm{kg})$ \\
\hline \multirow[t]{5}{*}{$40-49$ years $(n=10)$} & FFM by BIA & $47.79 \pm 7.32$ & - & - \\
\hline & Equation by Kulkarni et al. & $45.47 \pm 8.16$ & $-2.32(-4.821,0.175)$ & $2.62(-4.549,-0.091)$ \\
\hline & Equation by Solomon Yu et al. & $49.09 \pm 5.62$ & $1.29(-2.898,5.484)$ & $2.37(-0.939,3.519)$ \\
\hline & Janmahasatian equation & $49.07 \pm 7.94$ & $1.27(-0.422,2.967)$ & $1.51(-0.959,3.499)$ \\
\hline & Deurenberg equation & $48.03 \pm 8.39$ & $0.24(-2.340,2.812)$ & $1.24(-1.989,2.469)$ \\
\hline \multirow[t]{5}{*}{$50-59$ years $(n=15)$} & FFM by BIA & $43.68 \pm 6.47$ & - & - \\
\hline & Equation by Kulkarni et al. & $43.55 \pm 6.71$ & $-0.13(-4.574,4.313)$ & $2.19(-2.359,2.099)$ \\
\hline & Equation by Solomon Yu et al. & $47.93 \pm 4.38$ & $4.25(-1.555,10.050)$ & $5.09(2.021,6.479)$ \\
\hline & Janmahasatian equation & $47.51 \pm 6.76$ & $3.83(-0.006,7.661)$ & $4.27(1.601,6.059)$ \\
\hline & Deurenberg equation & $44.85 \pm 6.93$ & $1.17(-2.506,4.851)$ & $2.13(-1.059,3.399)$ \\
\hline \multirow[t]{5}{*}{$60-69$ years $(n=32)$} & FFM by BIA & $43.08 \pm 6.25$ & - & - \\
\hline & Equation by Kulkarni et al. & $42.70 \pm 6.20$ & $-0.38(-4.831,4.080)$ & $2.27(-2.609,1.849)$ \\
\hline & Equation by Solomon Yu et al. & $47.42 \pm 3.86$ & $4.34(-1.954,10.636)$ & $5.33(2.111,6.569)$ \\
\hline & Janmahasatian equation & $46.93 \pm 6.31$ & $3.85(-0.199,7.902)$ & $4.36(1.621,6.079)$ \\
\hline & Deurenberg equation & $43.05 \pm 6.30$ & $-0.03(-3.991,3.940)$ & $1.95(-2.259,2.199)$ \\
\hline \multirow[t]{5}{*}{$70-75$ years $(n=15)$} & FFM by BIA & $43.92 \pm 7.65$ & - & - \\
\hline & Equation by Kulkarni et al. & $44.84 \pm 7.73$ & $0.92(-3.709,5.541)$ & $2.46(-1.309,3.149)$ \\
\hline & Equation by Solomon Yu et al. & $48.70 \pm 4.60$ & $4.78(-2.481,12.038)$ & $5.93(2.551,7.009)$ \\
\hline & Janmahasatian equation & $49.06 \pm 7.52$ & $5.14(1.723,8.554)$ & $5.41(2.911,7.369)$ \\
\hline & Deurenberg equation & $44.13 \pm 7.84$ & $0.2(-2.992,3.402)$ & $1.56(-2.029,2.429)$ \\
\hline
\end{tabular}

$\mathrm{BMI}=$ body mass index $\mathrm{FFM}=$ fat-free mass in $\mathrm{kg}, \mathrm{RMSE}=$ root mean square error, $\mathrm{BIA}=$ bioelectrical impedance analysis, $\mathrm{CI}=$ confidence intervals.

evident by the lowest mean error and RMSE values. Underestimation of FFM was evident by the Kulkarni et al. equation, and overestimation was observed by the equations of $\mathrm{Yu}$ et al. and Janmahasatian equation in this group. In the age group of 50-59 years, the equation by Kulkarni et al. had the least mean error, whereas all other equations overestimated the FFM. Deurenberg equation and the equation by Kulkarni et al. had the lowest RMSE values, but the latter had a better precision. In the age group of 60-69 years, the Deurenberg equation and the equation by Kulkarni et al. had the least mean error and RMSE values, whereas the other three equations overestimated the FFM. Considering the mean error, 95\% CI of mean error and RMSE values, the 
Srigiripura, et al.: Bland-Altman plots of fat-free mass prediction equations

Deurenberg equation performed the best in the 40-49, 50-59 and 70-75 years sub-groups followed by the equation of Kulkarni et al. across the 50-79 years sub-group. An overestimation of FFM was evident in the values predicted by the Janmahasatian and Yu et al. predictive equations.

\section{DISCUSSION}

The objective of this study was to analyse the performance of prediction equations in predicting the FFM considering FFM estimated by BIA as standard in patients with COPD, which is of importance in the assessment of nutritional status and the provision of nutrition therapy.

In the current study, we found a better agreement of predicted FFM values by the Deurenberg equation and the equation by Kulkarni et al. with FFM by BIA as demonstrated by a lesser mean error of 0.31 and $-0.33 \mathrm{~kg}$, respectively and RMSE values of 1.83 and $2.35 \mathrm{~kg}$, respectively. The bias in the prediction was considered to be absent because the limits of agreement included zero. Researchers have used 'healthy participants' to frame the predictive equations, which could mean that factors related to changes in body composition could not be expected to be equal. The participants in this study had chronic illness associated with the respiratory system that is known to have a marked impact on the body composition and nutritional status.

The prediction equations by Kulkarni et al. were derived using 2364 Indian participants of both genders with normal health. The age of the participants ranged between 18 and 79 years and BMI between 14 and $44 \mathrm{~kg} / \mathrm{m}^{2}$. The study by $\mathrm{Yu}$ et al. included 52 Caucasians of both genders with normal health for the derivation of the equation. The equations derived were validated further in a cohort of 2287 people aged more than 50 years. The mean age was $50.6 \pm 15.7$ years in the base group, and the mean BMI of the participants was $23.7 \pm 2.3 \mathrm{~kg} / \mathrm{m}^{2}$. The validation group included participants aged above 80 years and a higher proportion of patients who were overweight and obese as compared to our study group. The Janmahasatian equation was derived from 373 healthy participants aged between 18 and 82 years, with BMI ranging from 17.1 to $69.9 \mathrm{~kg} / \mathrm{m}^{2}$. Among these, $71 \%$ of the patients had BMI above $25 \mathrm{~kg} / \mathrm{m}^{2}$ indicating majority of the participants to be overweight or obese as compared to $25 \%$ of participants who were overweight and obese in our study. The Deurenberg equation was derived separately for children and adults from a group of 1229 healthy participants from Netherlands comprising both genders, aged between 7 and 83 years and having a BMI ranging between 13.9 and $40.9 \mathrm{~kg} / \mathrm{m}^{2}$. The participants in the study by Kulkarni et al. and Deurenberg et al. had a wider age range and a higher degree of patients who were obese as compared to our study group. It is interesting to note that the Deurenberg equation, originally derived from the Dutch population, performed well on the participants in our study hailing from South
India. The Janmahasatian equation and the equation by $\mathrm{Yu}$ et al. exhibited a constant overestimation of FFM values.

The pattern of over- or underestimation observed in the prediction of FFM by these equations may arise from differences in the population race, demographic characteristics such as age and BMI clinical status among the study groups. The proportion of malnourished to normally nourished patients in the study groups and the difference in BMI classification norms applied could also be the reason for the alteration in performances (BMI classification norms for the south Asian population used in our study group vs. the general classification norms in the reference study groups). Although the Deurenberg equation and the equation by Kulkarni et al. performed well overall, the performance among sub-groups is inconsistent. Considering the need for accuracy in determining the FFM of a specific patient undergoing assessment in a clinical setting, the predictive performance across various age and BMI groups is necessary besides the overall performance in a heterogeneous population with respect to the nutritional status and age.

To our knowledge, this is the first study evaluating the performance of the selected predictive equations in South Indian patients with COPD for predicting FFM. The Deurenberg equation is used to predict fat mass routinely in clinical practice, and the performance of the same has been evaluated in comparison with equations derived from Indian participants. ${ }^{[21,22]}$ However, studies using Deurenberg equation to derive FFM from fat mass values are not reported. The limitations of the study include the absence of female patients in the study group and insufficient sample size in the sub-groups. The application of the validated equations in other population groups across the country may require further validation.

\section{Conclusion}

In summary, the equation by Kulkarni et al. and the Deurenberg equation can be useful in a clinical setting lacking advanced and specific equipment for FFM analysis such as BIA. Although these equations provide agreeable performance as evidenced by lower bias, better precision and accuracy on a whole, inconsistency in performance is evident across specific age and BMI sub-groups. The equation by Kulkarni et al. provides agreeable performance in patients aged between 50 and 69 years, and the Deurenberg equation can predict FFM accurately in patients aged between 40-49 years and 60-75 years. The performance of these two equations is agreeable in the patients who are underweight and those with normal BMI. The performance across overweight and obese groups requires further validation because of the lack of sufficient sample size. This study supports the assessment of body composition as a simple marker of nutrition depletion and disease severity in COPD staging.

\section{Acknowledgements}

We thank Dr. Santosha C.D., All India Institute of Speech and Hearing (AIISH), Mysuru, Karnataka, India for his help in 
statistical analysis. We also appreciate the willingness of the volunteers to participate in this study.

\section{Financial support and sponsorship}

We are grateful to the University Grants Commission Special Assistance Program - Phase II from the Department of Science \& Technology, Ministry of Science $\&$ Technology, India for funding the current study.

\section{Conflicts of interest}

There are no conflicts of interest.

\section{REFERENCES}

1. World Health Organization. The Top 10 Causes of Death. WHO; 2017 [updated Jan 2017]. Available from: http://www.who.int/mediacentre/ factsheets/fs310/en/. [Last accessed on 2017 May 3].

2. Sin DD, Man SF. Skeletal muscle weakness, reduced exercise tolerance, and COPD: Is systemic inflammation the missing link? Thorax 2006;61:1-3.

3. Ellis KJ, Eastman JD, editors. Human Body Composition: In Vivo Methods, Models, and Assessment. New York: Springer Science; 1993. p. 31-9.

4. Schols AM, Broekhuizen R, Weling-Scheepers CA, Wouters EF. Body composition and mortality in chronic obstructive pulmonary disease. Am J Clin Nutr 2005;82:53-9.

5. Vestbo J, Prescott E, Almdal T, Dahl M, Nordestgaard BG, Andersen $\mathrm{T}$, et al. Body mass, fat-free body mass, and prognosis in patients with chronic obstructive pulmonary disease from a random population sample: Findings from the Copenhagen City Heart Study. Am J Respir Crit Care Med 2006;173:79-83.

6. Mostert R, Goris A, Weling-Scheepers CA, Wouters EF, Schols AM. Tissue depletion and health related quality of life in patients with chronic obstructive pulmonary disease. Respir Med 2000;94:859-67.

7. Pothirat CM, Chaiwong W, Phetsuk N, Liwsrisakun C, Bumroongkit $\mathrm{C}$, Deesomchok A, et al. The relationship between body composition and clinical parameters in chronic obstructive pulmonary disease. $\mathrm{J}$ Med Assoc Thai 2016;99:386-93.

8. Miller A, Strauss BJ, Mol S, Kyoong A, Holmes PH, Finlay P, et al. Dual-energy X-ray absorptiometry is the method of choice to assess body composition in COPD. Respirology 2009;14:411-8.

9. Duren DL, Sherwood RJ, Czerwinski SA, Lee M, Choh AC, Siervogel RM, et al. Body composition methods: Comparisons and interpretation. J Diabetes Sci Technol 2008;2:1139-46,

10. Bosy-Westphal A, Later W, Hitze B, Sato T, Kossel E, Glüer CC, et al. Accuracy of bioelectrical impedance consumer devices for measurement of body composition in comparison to whole body magnetic resonance imaging and dual X-ray absorptiometry. Obes Facts 2008;1:319-24.

11. Rabe KF, Hurd S, Anzueto A, Barnes PJ, Buist SA, Calverley P, et al. Global strategy for the diagnosis, management, and prevention of chronic obstructive pulmonary disease: GOLD executive summary. Am J Respir Crit Care Med 2007;176:532-55.

12. National Institutes of Health. Bioelectrical Impedance Analysis in Body Composition Measurement: National Institutes of Health Technology Assessment Conference Statement [About 3 Screens]. US: NIH Consensus Development Program; 1994. Available from: https://consensus.nih.gov/1994/1994BioelectricImpedanceBodyta015 html.htm. [Last accessed on 2016 Oct 20].

13. Kulkarni B, Kuper H, Taylor A, Wells JC, Radhakrishna KV, Kinra $\mathrm{S}$, et al. Development and validation of anthropometric prediction equations for estimation of lean body mass and appendicular lean soft tissue in Indian men and women. J Appl Physiol 2013; 115:1156-62.

14. Yu S, Visvanathan T, Field J, Ward LC, Chapman I, Adams R, et al. Lean body mass: The development and validation of prediction equations in healthy adults. BMC Pharmacol Toxicol 2013;14:1.

15. Janmahasatian S, Duffull SB, Ash S, Ward LC, Byrne NM, Green B. Quantification of lean bodyweight. Clin Pharmacokinet 2005;44: 1051-65.

16. Deurenberg P, Weststrate JA, Seidell JC. Body mass index as a measure of body fatness: Age- and sex-specific prediction formulas. Br J Nutr 1991;65:105-14.

17. Bland JM, Altman D. Statistical methods for assessing agreement between two methods of clinical measurement. Lancet 1986; 327:307-10.

18. Giavarina D. Understanding Bland-Altman analysis. Biochem Med 2015;25:141-51.

19. Walther BA, Moore JL. The concepts of bias, precision and accuracy, and their use in testing the performance of species richness estimators, with a literature review of estimator performance. Ecography 2005; 28:815-29.

20. Misra A, Chowbey P, Makkar BM, Vikram NK, Wasir JS, Chadha D, et al. Consensus statement for diagnosis of obesity, abdominal obesity and the metabolic syndrome for Asian Indians and recommendations for physical activity, medical and surgical management. J Assoc Physicians India 2009;57:163-70.

21. Deurenberg P, Deurenberg-Yap M. Validation of skinfold thickness and hand-held impedance measurements for estimation of body fat percentage among Singaporean, Chinese, Malay and Indian subjects. Asia Pac J Clin Nutr 2002;11:1-7.

22. Chahar PS. Assessment of body fat percentage by different methods: A comparative study. Eur J Sport Sci 2014;3:1-6. 